\title{
Evidence and the patient's role in safer care
}

\section{David P Stevens}

I will never forget the frigid snowy February day when I was to make the 30 min flight to Boston from the island where I live. This local airline uses nineseat twin-engine planes, the last of which came off the assembly line in the mid1980s. The ninth passenger sits in the co-pilot's seat. The temperature was subfreezing-where ice formation on the wings is a safety concern because it reduces the plane's lift.

I was the only passenger that day. The young pilot walked through the waiting area with a window scraper, the kind I had used to clean the ice off my car windows that morning. She smiled and said, 'gotta de-ice this puppy.' I must have blanched because she later walked back into the waiting area and nodded toward me again. 'Don't worry doc, I'm going too.' I assumed this was intended to reassure me. And it did. I think. It reminded me once again that one of the big differences between airline safety, which we reference so often, and patient safety, is that the pilot has a vested interest in a safe flight. One macabre pilot-friend of mine likes to say, "we care about a safe flight because the pilot is always the first person on the scene of the accident.'

The IOM Chasm Report, ${ }^{1}$ which anchors much of healthcare improvement theory emphasises patient-centredness as one of the six dimensions for a better health system. It shines a light on the power of the patient and their vested interest in improving care outcomes.

But where does the patient fit in strategies to make their care safer? No one has a greater vested interest than the patient,

Correspondence to Dr David P Stevens, Dartmouth Institute for Health Policy and Clinical Care, 30 Lafayette Street, Lebanon, NH 03766, USA; david.p.stevens@ dartmouth.edu. but it is not that simple. A patient who questions ('Doctor, did you wash your hands?') or seems to comment critically ('Nurse, that doesn't look like the pill I take at home.') is always mindful of the hierarchy that exists in the world of healthcare.

Doctors and nurses have a personal commitment to their patient's safe care. They suffer when their patients are harmed. ${ }^{2}$ Students see aspects of patient safety with eyes that are fresh and penetrating. ${ }^{3}$ But critical research is thin in the area of the patient's role.

Leape and colleagues ${ }^{4}$ recently characterised three areas where patients have such a role: the need for systems to bring patients into a safe culture of care; the central place for families' closeness to the patient's care; and the importance of patients in sharing fully in decisions. These three aspects of patient involvement offer strategies that provide support for the patient in the hierarchy. But we need more. We need the evidence for how this works.

This issue of Quality and Safety in Health Care features two reviews of the patient safety literature in this regard. Masso Guijarro and colleagues (see page 144) call for more specific and explicit theory with which to study a role for patients in their own safe care. ${ }^{5}$ The literature review by Ansermino et al (see page 148) emphasises the importance of knowing how to bring the patient into the safety conversation to contribute validly to their own safety. ${ }^{6}$ Both reviews suggest a simple messagethe study of patient safety calls for critical research that defines more accurately the role for patients and their families in safer care.

There are many approaches that could help define an effective role for patients. Here are four specific examples where we need the evidence. Do open visiting hours for families actually make care safer for patients on ICUs ${ }^{7}$ ? Is there a defined and measurable role for the patient in institutional safety culture? ${ }^{8}$ The patient is an integral part of a high-performing clinical microsystem, but will surveys of patient experience in such settings provide mechanisms for how that patient role makes the microsystem safer? ${ }^{9}$ Does selfmanagement for the chronically ill patient-a central component of the Chronic Care Model-make his or her care safer? ${ }^{10}$ I have a strong bias that the answer to all these questions is yes. But we need the data to support the theories.

Most experts believe that patients have a place in making care safer. We need to know how this contributes to safer care, because, unlike the young pilot that February morning, when it comes to safer healthcare, 'Don't worry doc, I'm going too' is still only true for patients.

Competing interests The author is editor-in-chief of Quality and Safety in Health Care.

Provenance and peer review Not commissioned; not externally peer reviewed.

Oual Saf Health Care 2010;19:82.

doi:10.1136/ashc. 2010.042473

\section{REFERENCES}

1. Crossing the quality chasm. A new health systefor the 21st century. Washington, DC: National Academies Press, 2001.

2. Scott SD, Hirschinger $L E$, Cox $K R$, et al. The natural history of recovery for the healthcare provider 'second victim' after adverse patient events. Qual Saf Health Care 2009;18:325-30.

3. Seiden SC, Galvan C, Lamm R. Role of medical students in preventing harm and enhancing patient safety. Qual Saf Health Care 2006;15:272-6.

4. Leape L, Berwick D, Clancy C, et al. Transforming health care: a safety imperative. Oual Saf Health Care 2009;18:424-8.

5. Masso Guijarro P, Aranaz Andres JM, Mir JJ, et al Adverse events in hospitals: the patient's point of view. Qual Saf Health Care 2010;19:144-147.

6. Ansermino JM, King A, Daniels J, et al. Time to listen: a review of methods to solicit patient reports of adverse events. Qual Saf Health Care 2010;19:148-157.

7. Berwick D, Kotagal M. Restricting visiting hours in ICUs: time to change. JAMA 2004:292:736-7.

8. Pronovost P, Sexton B. Assessing safety culture guidelines and recommendations. Qual Saf Health Care 2005;14:231-3.

9. Wasson JH, Godfrey MM, Nelson EC, et al. Microsystems in health care: planning patientcentered care. Joint Comm J Qual Saf 2003;29:227-37.

10. Bodenheimer T, et al. Patient self-management of chronic disease in primary care. JAMA 2002;282:2469-75. 